\title{
3rd INTERNATIONAL CONGRESS OF PERSON CENTERED MEDICINE
}

\author{
AND \\ IST INTERNATIONAL CONFERENCE \\ OF \\ PRIMARY CARE AND PUBLIC HEALTH
}
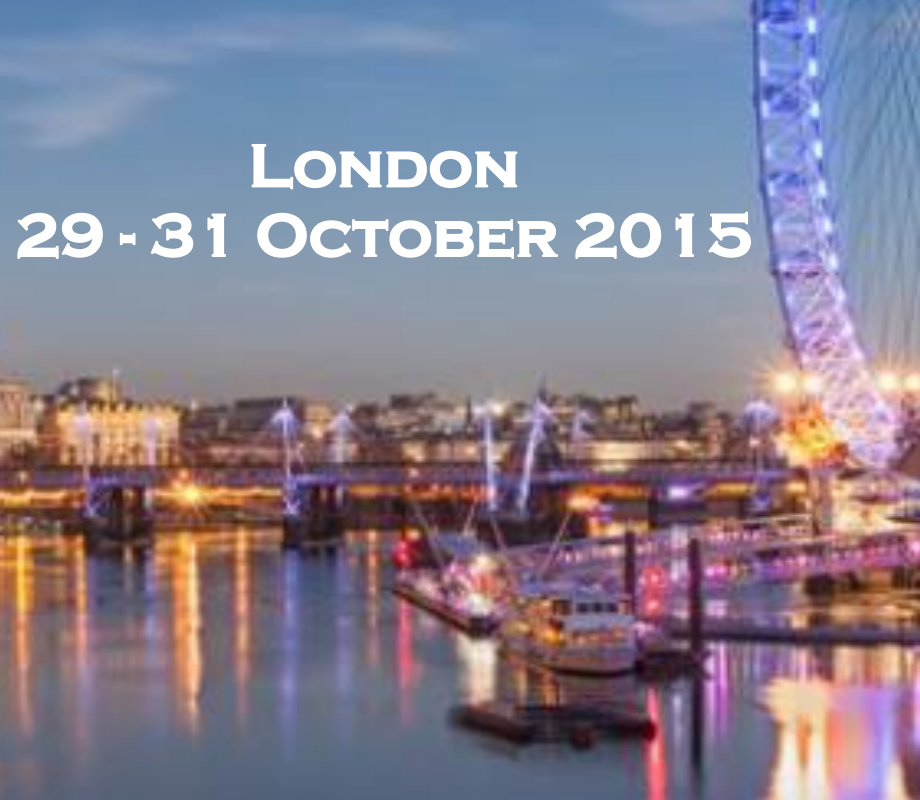

CELEBRATING PRIMARY CARE ACHIEVEMENTS

Seeing the person behind the patient through the life course

\section{Imperial College \\ VENUE} London

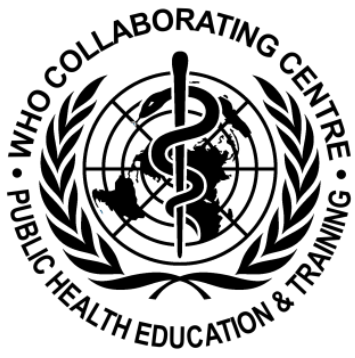

Great Hall, South Ken Campus Imperial College London London, UK

ICPCMLondon2015.org IJPCM.org Personcenteredmedicine.org

\section{THEMES}

- Primary Care in the 21st Century (NCDs, Diabetes, Health checks)

- Ageing and Ageism

- Childhood \& Adolescence

- Integrated Care

- Public Health in Primary Care CROSS-CUTTING THEMES

- Education \& Training

- Research 